\title{
Mentoring Model in an Active Learning Culture for Undergraduate Projects
}

\author{
Wongpanya Nuankaew ${ }^{1}$, Kanakarn Phanniphong ${ }^{2}$, Sittichai Bussaman ${ }^{3}$, Direk Teeraputon ${ }^{4}$, and Pratya Nuankaew ${ }^{5, *}$ \\ ${ }^{1}$ Faculty of Information Technology, Rajabhat Mahasarakham University, Maha Sarakham, 44000, Thailand \\ ${ }^{2}$ Faculty of Business Administration and Information Technology, Rajamangala University of Technology Tawan-Ok, Chonburi, \\ 20110, Thailand
}

${ }^{3}$ Faculty of Science and Technology, Rajabhat Mahasarakham University, Maha Sarakham, 44000, Thailand

${ }^{4}$ School of Education, University of Phayao, Phayao, 56000, Thailand

${ }^{5}$ School of Information and Communication Technology, University of Phayao, Phayao, 56000, Thailand

\section{A R T I C L E I N F O}

Article history:

Received: 17 June, 2020

Accepted: 17 August, 2020

Online: 28 August, 2020

Keywords:

Active Learning Culture

Educational Data Mining

Engineering Education

Learning Analytics

Lifelong Learning

Mentoring Model

\begin{abstract}
A B S T R A C T
Senior projects allow students to move the learning process from basic knowledge to an interdisciplinary approach. The purpose of this research is (1) to analysis attitude and perception, which is a collaboration between teachers and students to develop a model for clustering of appropriate advisors and advisee who cooperate in senior project, and (2) to develop factors that are significant to predict the right match in senior projects course. Data collection was a questionnaire consisting of 463 samples from 7 administrators, 68 lecturers, 26 staff and 362 students from two institutions: The Rajabhat Mahasarakham University, and the University of Phayao. The research methodology was designed and divided into three sections: preparation, implementation, and conclusion. The result shows that the satisfaction and the overall acceptance level were at a high level (mean $=4.04$, S.D. = 0.88). Moreover, the developed model has the highest level of efficiency (accuracy $=98.06 \%)$. While the factors that are important for matching recommendations consists of 9 factors: policies of the organization, vision of the organization, mission of the organization, experience and achievements of researchers, qualifications of research team, interest in the research topics, impressions and examples in the past, technology and laboratory support, and budget support. For the future, the researchers are aimed to research on the development of students' academic achievement and aims to promote a learning culture based on the results of this research.
\end{abstract}

\section{Introduction}

In the world of learning and educational theories, developing learners to understand research problems and constructing the concepts to create research problems is most difficult and complicated in managing. Learners often have different learning styles, which are classified according to learner characteristics [14]. At the same time teachers have skills, abilities, experience, knowledge, expertise, and aptitude in different contexts [1]. Thus,

${ }^{*}$ Corresponding Author: Pratya Nuankaew, School of Information and Communication Technology, University of Phayao, Phayao, 56000, Thailand, +66 899614832 \& pratya.nu@up.ac.th the response that occurs between the student and the teacher is important. It can also be used to develop a structured relationship for collaboration between students and teachers through feedback and perception of both parties [3,4].

The problem is related to the context of the curriculum that has been instructed in the field of information technology and other disciplines, which is concerned with the development of students' knowledge by using senior projects as a knowledge base learning [5]. However, a popular and applied method for developing an effective educational process is proactive learning [6] and proactive learning culture [7]. 


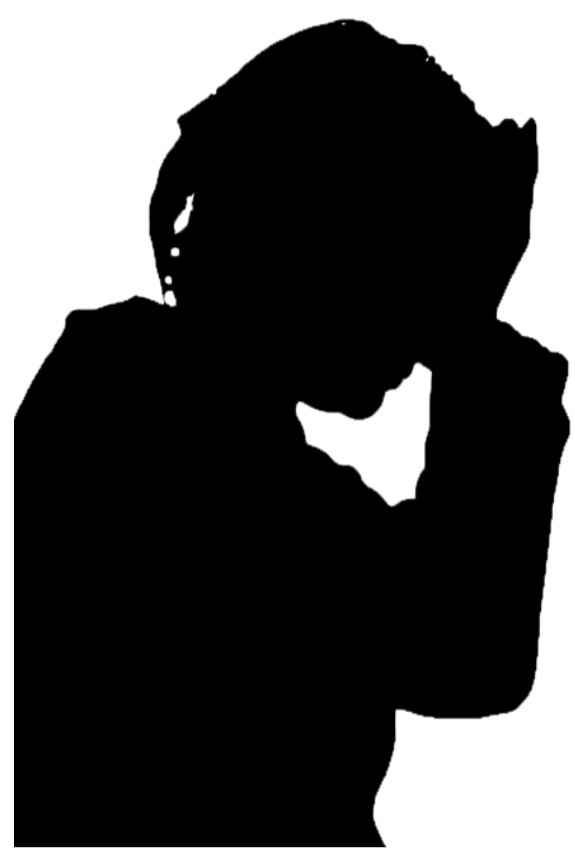

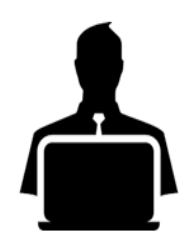

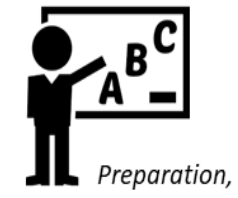

teaching and lectures

Checking Homework and Assignments

\section{The Duties of}

\section{University Researchers}

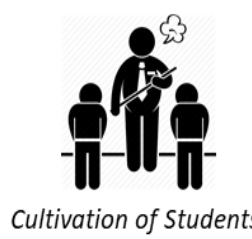

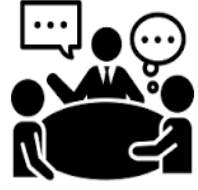

Group Discussions and Senior Projects

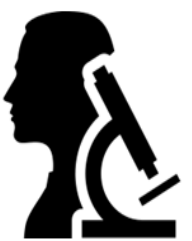

Study and Research

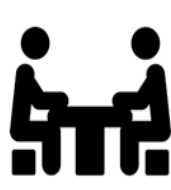

Counseling

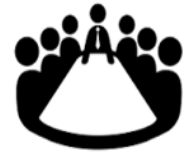

Meeting

Figure 1: The Duties of University Researchers

Proactive learning or active learning is an essential feature of a person in a learning society that is aware of and responds to many events and stimuli. Having a proactive feature will allow the person to behave appropriately and produce good results. In the active learning perspective, learners play a role in acquiring knowledge and learning in an interactive way until knowledge and understanding are applied, able to analyze, synthesize, evaluate or create things and develop themselves to their full potential.

As well as organizing a learning experience to participate in discussions to practice communication skills, resulting in a high learning result [8-13]. Key aspects of learning management of active learning concepts that emphasize the role and participation of the learners. Knowledge arises from experience, building knowledge, and reviewing learners. In addition, it is a learning management aimed at developing brain potential. Learning management that allows learners to participate in learning The process of creating situations for learners and emphasizing advanced thinking skills [8-10]. It can be concluded that active learning is not only for learner development but also being used for industry development [11-12].

In addition, to creating a learning culture that promotes critical and analytical thinking [8] there needs to be a concrete order for the learner to understand the process of the problem and the solution. According to the intentions of the curriculum for modern education [1,2,9-12], it changed the role of instructors and learners to become colleagues, which is a matter of knowing and cooperating. The instructor is not responsible for educating the learner anymore. The instructor acts as a coach that guides players to play only.

At the same time, the students need to solve a specific problem in the educational problems. It seems that students will need to find www.astesj.com solutions to educational problems in their quest to understand their own thinking processes and knowledge.

Moreover, the vast majority of researchers at the university need to perform teaching tasks, which spend most of their time for preparing in learning management and summarizing students' tasks as demonstrated in Figure 1. Teachers also need more time to evaluate the learner outcomes. This corresponds to the problem on students who wish to perform well with their senior project.

Figure 1 presents an overview of the duties and responsibilities of most researchers at universities in Thailand. It consists of teaching, conducting research, student counseling, planning classroom management, meetings, promoting students' intrinsic motivation, and so on. It seems that teachers have little time to support student projects. Whereas the collaboration of teachers and students used in senior project development consists of five phases as shown in Figure 2.

Figure 2 shows the senior project development phase which consists of five phases. Phase 1: The process of discovering senior projects based on the student's interests, relevant to teacher research and teacher interest, and the appropriate competence of the faculty member in the organization. Phase 2 : The process of transferring academic results, knowledge, interests, sharing, planning, group discussion, and senior project framework development. Phase 3: Development phase, which will be in a long period of time. Phase 4: Project effectiveness testing and evaluation phase, which will test the project for improvement. Phase 5: The publishing process, which presents knowledge and new discoveries obtained from the project. All five phases need to be completed in two semesters or approximately eight months. 

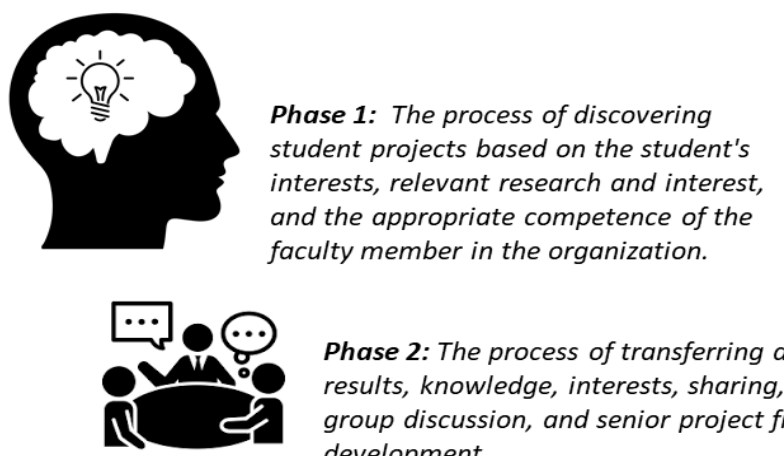

Phase 2: The process of transferring academic results, knowledge, interests, sharing, planning, group discussion, and senior project framework development.

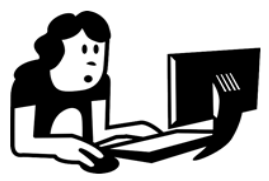

Phase 3: Development Phase

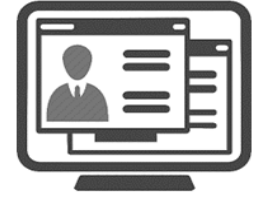

Phase 4: Project Effectiveness Testing and Evaluation Phase
The Collaboration

\section{between students and teachers to develop a senior project.}

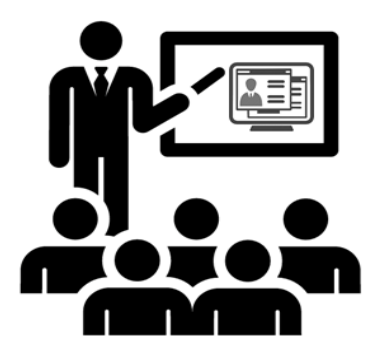

Phase 5: The publishing process, which is the process of presenting knowledge and new discoveries obtained from the project.

Figure 2: Senior Project Development Process

Considering the abundant and heavy workload of the teacher and the limitations for the development of student projects, adopting proactive learning by creating an appropriate learning culture is important. More than that, the reason for the researchers who emphasized the model development and data analysis in this study was because the research team assembled teams from many institutions, but encountered the same problem. Our common problem is to recommend suitable teachers to students in senior projects. It is important, but difficult. Therefore, this research focused on solving problems proactively using proactive learning strategies to create opportunities for corrective action and reduce impropriety. In addition, the professional group of the researchers is in the information technology field, as researchers try to use technology to help solve the problems. The purpose of this research is (1) to analyze the attitude and perception, which is a collaboration between teachers and students to develop a model for the clustering of appropriate advisors and advisee who cooperate in the senior project, and (2) to develop factors that are significant to predict the right match in senior projects course. Moreover, the major goal of the research team is to develop a student proactive learning culture in educational institutions, which is planned for future research.

The research outline consists of five parts: a summary of the relevant research in Section 2, data collection and research methodology is presented in Section 3, research results and discussion reports are provided in Section 4. Finally, the conclusion is summarized in Section 5, respectively.

\section{Literature Reviews}

\subsection{Cooperative Learning}

Cooperative learning model is one of the learning style that aims to communicate and collaborate with both parties on academic achievements. In addtion, cooperative learning is a learning activity technique that allows students to learn together in small groups, each made up of members with different abilities.
Each person is truly involved in learning [17-19]. In the group's learning and success, where the group exchanges views, shares resources, encourages one another, group members are not only responsible for their own grades but are also responsible for their own performance. Learn of all fellow members of the group, it can be called individual success, group success.

Examples of research work related to the concept of cooperative learning such as eL-PCDA model that management cooperative learning in e-Learning, based on learner's behavioral environment, scheduling, and monitoring of learning activities for cooperative learning [18]. Anothor example is the multi-agent system (MAS) that instead of single-agent learning to handle the performance enhancement of cooperative learning for decision making [18]. The last example is the multi-user streaming feedback system for cooperative learning application whereas teachers can monitor their students and problems in real-time, and the students have more willingness towards learning [13]. Obviously, the demonstration shows that cooperative learning can be a learning achievement, which is important in including goals that both parties emphasize.

\subsection{Practical Learning}

Practical learning is a way of learning from experience. Because work is more problematic than problem solving, it requires more than opening the textbook. It's important for learners to find a way to solve the problem appropriately be correct and reasonable, as well as being useful and applicable [20-23].

Practical learning is learning through experience, the theories used in learning management are Kolb's experiential leaning theory [1-2]. Kolb defines learning as a process in which knowledge is created through the transformation of experience. Learning can be explained in four main steps: Concrete Experience (CE), Reflection Observation (RO), Abstract Conceptualization 


\section{Research Methodology and Scope}

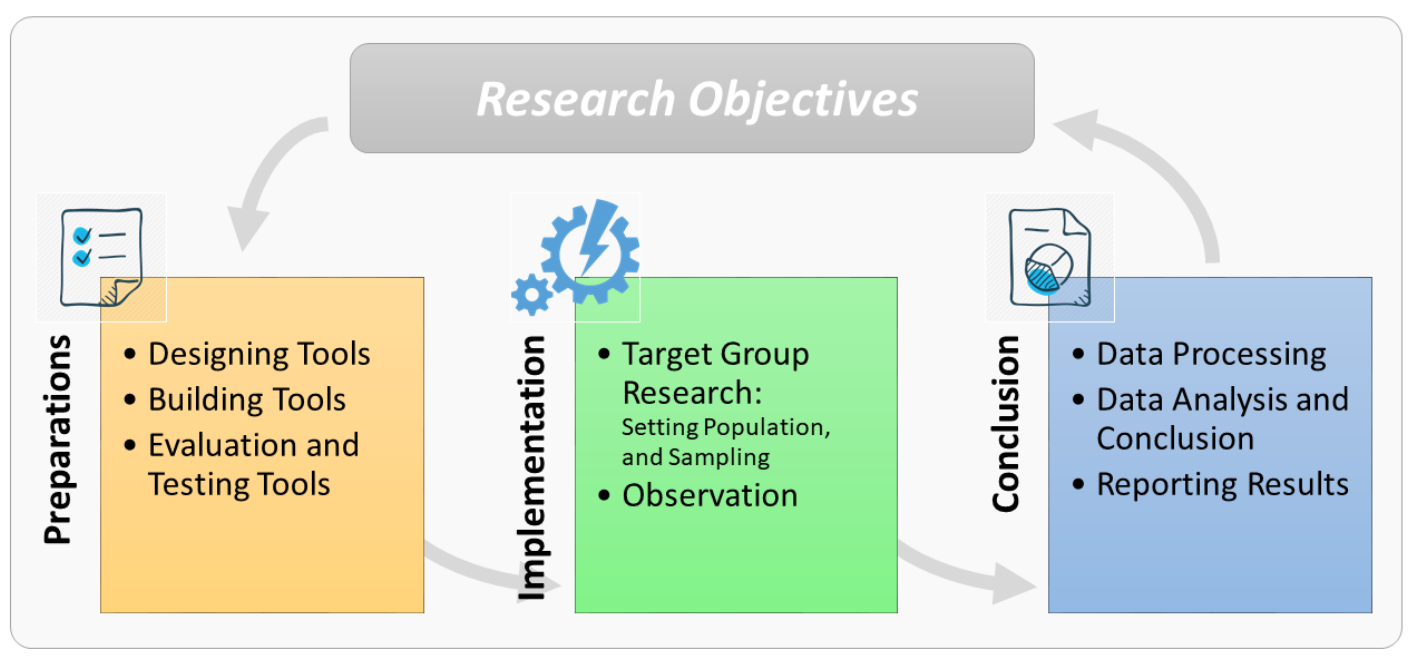

Figure 3: Research Methodology

(AC), and Active Experimentation (AE). Which is evident that learning from practice requires the use of knowledge and experience, which will help develop the learners' attitudes and behavior towards an important goal of learning.

However, practical learning is not just a matter of practice, it must Research Methodology

The research methodology is designed and shown in Figure 3.

\subsection{Research Objectives}

The purpose of the research is (1) to make an analysis on the attitude and perception, which is a collaboration between teachers and students to develop a model for the clustering of appropriate advisors and advisee who cooperate in the senior project, and (2) to develop factors that are significant to predict the right match in senior projects course.

\subsection{Research Preparation}

1) Designing Tools

At the stage of designing tools, the researchers conducted a preliminary study of the research process used for finding attitudes and satisfaction, which found that the appropriate and interesting tool was a questionnaire. Researchers examined questionnaires through the researcher's organization according to procedures and standards of the research process. Questionnaires are routinely used to assess teaching and learning. It is conducted on an annual basis. In addition, the questionnaire quality assessment is described in the review stage section.

At the same time, the data used in the analysis and design of the questionnaire were used by interviewers, including teachers who had received research grants, students who presented and published senior projects, and university administrators.

\section{2) Building Tools}

In the process of building tools, the questionnaire was designed into 3 parts, including, Part 1: General information of the respondents, Part 2: Satisfaction and Attitude Towards Senior www.astesj.com
Projects, and Part 3: Suggestions for Senior Projects. While the main topic of part 2 is shown in Table 1.

Table 1: Issues and Essence on Senior Projects

\begin{tabular}{|l|l|}
\hline Main Essence & Dimensions Related to Essence: Sub-Stages \\
\hline 1. Organization & $\begin{array}{l}\text { 1.1 The policies of the organization } \\
\text { 1.2 The vision of the organization } \\
\text { 1.3 The mission of the organization } \\
\text { 1.4 Management and support of the organization }\end{array}$ \\
\hline 2. Researcher & $\begin{array}{l}\text { 2.1 Experience and achievements of researchers } \\
\text { 2.2 Aptitude and expertise of researchers } \\
\text { 2.3 Qualifications of Research Team }\end{array}$ \\
\hline 3. Students & $\begin{array}{l}\text { 3.1 Knowledge and ability of learners } \\
\text { 3.2 Interest in the research topics } \\
\text { 3.3 Impressions and examples in the past }\end{array}$ \\
\hline 4. Project Support & 4.1 Technology and laboratory support \\
& $\begin{array}{l}\text { 4.2 Staff support } \\
\text { 4.3 Budget support }\end{array}$ \\
\hline
\end{tabular}

The essence of Part 2 is to find out the level of opinion and attitude on the factor that encourage learners and teachers to collaborate on research, which is comprised of four main areas: organization, researcher, students and project support.

\section{3) Review Stage}

After designing and constructing the tool, it was tested for confidence and accuracy by 3 experts from the Department of Information Technology, Faculty of Information Technology, Rajabhat Mahasarakham University, Thailand.

\subsection{Evaluation and Testing Tools}

The research actions were divided into two phases: 1) Target group research, which describe and define the scope of data collection, 2) Research observation, which shows the process of conducting research and gathering data.

1) Target Group Research 


\section{a) Population}

Data gathering is done in all dimensions, which was limited to the area from two institutions: The Rajabhat Mahasarakham University, and the University of Phayao. The population was defined by four groups: administrators, lecturer, staff and students.

b) Sampling

Sampling was randomly selected from 463 samples, which had been divided into four groups: 7 administrators, 68 lecturers, 26 staff and 362 students.

2) Research Observation

a) Respond to the objectives

After completing the data collection the data sets were already considered as information which provided covers for the purpose of the research.

b) Meet the research framework

The data set responds to the research based on the research framework and is used to test the hypothesis in its entirety.

c) Proceed with caution

In gathering information, it will only attract the attention of the respondents and collected from the reality to get the information according to the actual situation.

\subsection{Research Conclusion}

\section{1) Data Processing}

At this stage, the instrument used for data analysis was selected, consisting of two parts: standard deviation (S.D.) and mean. Analysis of data was divided into groups and topics has been determined and summarized in the next section.

2) Data Analysis and Conclusion

The sample set from the 463 samples was analyzed and summarized as shown in Table 2 and Table 3.

Table 2: Data collection classified by gender

\begin{tabular}{|l|c|c|c|c|c|}
\hline \multirow{2}{*}{ Gender } & \multicolumn{5}{|c|}{ Samples $(\mathrm{n}=463)$} \\
\cline { 2 - 6 } & $\begin{array}{c}\text { Administrators } \\
\left(\mathrm{s}_{1}\right)\end{array}$ & $\begin{array}{c}\text { Lecturers } \\
\left(\mathrm{s}_{2}\right)\end{array}$ & $\begin{array}{c}\text { Staffs* } \\
\left(\mathrm{s}_{3}\right)\end{array}$ & $\begin{array}{c}\text { Students } \\
\left(\mathrm{s}_{4}\right)\end{array}$ & Total \\
\hline \multirow{2}{*}{ Male } & 4 & 27 & 13 & 141 & 185 \\
& $(0.86 \%)$ & $(5.83 \%)$ & $(2.81 \%)$ & $(30.45 \%)$ & $(39.96 \%)$ \\
\hline \multirow{2}{*}{ Female } & 3 & 41 & 13 & 221 & 278 \\
& $(0.65 \%)$ & $(8.86 \%)$ & $(2.81 \%)$ & $(47.73 \%)$ & $(60.04 \%)$ \\
\hline \multirow{2}{*}{ Total: } & 7 & 68 & $\begin{array}{c}26 \\
(1.51 \%)\end{array}$ & $\begin{array}{c}362 \\
(14.69 \%)\end{array}$ & $\begin{array}{c}463 \\
(1.62 \%)\end{array}$ \\
\hline \multicolumn{7}{|c|}{$*$ staffs $=$ Practitioners in the organization but not performing teaching dutie }
\end{tabular}

Table 2 shows that most of the respondents are female, with 278 people representing 60.04 percent of all data providers. The researchers found that it was consistent with the students at the University of Phayao and Rajabhat Mahasarakham University, which had mostly female students.

Table 3: Data collection classified by age

\begin{tabular}{|c|c|c|c|c|c|}
\hline \multirow{3}{*}{ Age } & \multicolumn{5}{|c|}{ Samples $(\mathrm{n}=463)$} \\
\cline { 2 - 6 } & $\begin{array}{c}\text { Administrators } \\
\left(\mathrm{s}_{1}\right)\end{array}$ & $\begin{array}{c}\text { Lecturers } \\
\left(\mathrm{s}_{2}\right)\end{array}$ & $\begin{array}{c}\text { Staffs } \\
\left(\mathrm{s}_{3}\right)\end{array}$ & $\begin{array}{c}\text { Students } \\
\left(\mathrm{s}_{4}\right)\end{array}$ & Total \\
\hline $\begin{array}{l}20-30 \\
\text { years old }\end{array}$ & 1 & 24 & 12 & 356 & 393 \\
$(0.22 \%)$ & $(5.18 \%)$ & $(2.59 \%)$ & $(76.89 \%)$ & $(84.88 \%)$ \\
\hline
\end{tabular}

\begin{tabular}{|c|c|c|c|c|c|}
\hline \multirow{3}{*}{ Age } & \multicolumn{5}{|c|}{ Samples (n=463) } \\
\cline { 2 - 6 } & $\begin{array}{c}\text { Administrators } \\
\left(\mathrm{s}_{1}\right)\end{array}$ & $\begin{array}{c}\text { Lecturers } \\
\left(\mathrm{s}_{2}\right)\end{array}$ & $\begin{array}{c}\text { Staffs } \\
\left(\mathrm{s}_{3}\right)\end{array}$ & $\begin{array}{c}\text { Students } \\
\left(\mathrm{s}_{4}\right)\end{array}$ & Total \\
\hline $31-40$ & 1 & 30 & 9 & 6 & 46 \\
years old & $(0.22 \%)$ & $(6.48 \%)$ & $(1.94 \%)$ & $(1.30 \%)$ & $(9.94 \%)$ \\
\hline $41-50$ & 1 & 11 & 44 & 0 & 16 \\
years old & $(0.22 \%)$ & $(2.38 \%)$ & $(0.86 \%)$ & $(0.00 \%)$ & $(3.46 \%)$ \\
\hline $51-60$ & 4 & 3 & 1 & 0 & 8 \\
years old & $(0.86 \%)$ & $(0.65 \%)$ & $(0.22 \%)$ & $(0.00 \%)$ & $(1.73 \%)$ \\
\hline Total : & 7 & 68 & 26 & 362 & 463 \\
$(1.51 \%)$ & $(14.69 \%)$ & $(5.62 \%)$ & $(78.19 \%)$ & $(100 \%)$ \\
\hline
\end{tabular}

Table 3 shows that the majority of data providers are between the ages of 20-30, with 393 people representing 84.88 percent of all data providers.

The researchers found that most of the respondents were between 20 and 30 years old, as it was the main target group the research focused on. However, other age groups are consistent with the target group, as it is the mentor group who provides consultation to the senior project.

Table 4: Data collection classified by education

\begin{tabular}{|c|c|c|c|c|c|}
\hline \multirow{2}{*}{ Education } & \multicolumn{5}{|c|}{ Samples $(\mathrm{n}=463)$} \\
\cline { 2 - 6 } & $\begin{array}{c}\text { Administrators } \\
\left(\mathrm{s}_{1}\right)\end{array}$ & $\begin{array}{c}\text { Lecturers } \\
\left(\mathrm{s}_{2}\right)\end{array}$ & $\begin{array}{c}\text { Staffs } \\
\left(\mathrm{s}_{3}\right)\end{array}$ & $\begin{array}{c}\text { Students } \\
\left(\mathrm{s}_{4}\right)\end{array}$ & Total \\
\hline Doctorate & 6 & 9 & 0 & 0 & 15 \\
$(1.30 \%)$ & $(1.94 \%)$ & $(0.00 \%)$ & $(0.00 \%)$ & $(3.24 \%)$ \\
\hline \multirow{2}{*}{ Master } & 1 & 55 & 14 & 6 & 76 \\
& $(0.22 \%)$ & $(11.88 \%)$ & $(3.02 \%)$ & $(1.30 \%)$ & $(16.41 \%)$ \\
\hline Bachelor & 0 & 4 & 12 & 356 & 372 \\
& $(0.00 \%)$ & $(0.86 \%)$ & $(2.59 \%)$ & $(76.89 \%)$ & $(80.35 \%)$ \\
\hline Total : & 7 & 68 & 26 & 362 & 463 \\
$(1.51 \%)$ & $(14.69 \%)$ & $(5.62 \%)$ & $(78.19 \%)$ & $(100 \%)$ \\
\hline
\end{tabular}

Table 4 shows that the majority of the data providers have a bachelor's degree, with 372 people representing 80.35 percent of all data providers. The researchers found that most of the respondents had a bachelor's degree because they were students of the primary target group. In addition, respondents with a master's and doctoral degree show the proportion of mentors.

In interpreting the data according to the characterization criteria, the interpretation is based on a five-level interpretation method by comparing it with the criteria that divides the level estimation into five equal levels, as followed in Equation (1). The result of the calculation is shown in Equation (2).

$$
\begin{aligned}
& \text { Width of the level }=\frac{\text { Maximum-Minimum }}{\text { Number of levels }} \\
& \text { Width of the level }=\frac{5-1}{5}=0.8
\end{aligned}
$$

From the calculation results in Equation (2), the interpretation results can be specified as shown in Table 5 .

Table 5: Interpretation and Meaning

\begin{tabular}{|c|c|c|}
\hline Width of the level & Interpretation & Meaning \\
\hline $1.00-1.80$ & Highly Unacceptable & $\begin{array}{c}\text { The lowest level of } \\
\text { satisfaction }\end{array}$ \\
\hline $1.81-2.60$ & Unacceptable & $\begin{array}{c}\text { Low level of } \\
\text { satisfaction }\end{array}$ \\
\hline $2.61-3.40$ & Acceptable & Satisfaction \\
\hline
\end{tabular}


W. Nuankaew et al. / Advances in Science, Technology and Engineering Systems Journal Vol. 5, No. 4, 805-815 (2020)

\begin{tabular}{|c|c|c|}
\hline Width of the level & Interpretation & Meaning \\
\hline $3.41-4.20$ & Highly Acceptable & $\begin{array}{c}\text { High level of } \\
\text { satisfaction }\end{array}$ \\
\hline $4.21-5.00$ & Maximum Acceptable & $\begin{array}{c}\text { The highest level of } \\
\text { satisfaction }\end{array}$ \\
\hline
\end{tabular}

Table 6: Satisfaction and acceptance toward the factors

\begin{tabular}{|c|c|c|c|c|c|c|c|}
\hline \multirow{3}{*}{ Stages } & \multicolumn{6}{|c|}{ Satisfaction and Acceptance $(\mathrm{n}=463)$} \\
\cline { 2 - 7 } & $s_{1}$ & $s_{2}$ & $s_{3}$ & $s_{4}$ & $\begin{array}{c}\text { Total } \\
\text { Mean }\end{array}$ & $\begin{array}{c}\text { Total } \\
\text { S.D. }\end{array}$ & Interpretation \\
\hline
\end{tabular}

\begin{tabular}{|c|c|c|c|c|c|c|c|}
\multicolumn{6}{|c|}{ Stage 1 : Organization } \\
\hline Stage 1.1 & 3.71 & 2.87 & 3.04 & 3.69 & 3.53 & 1.12 & $\begin{array}{c}\text { Highly } \\
\text { Acceptable }\end{array}$ \\
\hline Stage 1.2 & 3.86 & 3.43 & 3.39 & 3.98 & 3.86 & 0.92 & $\begin{array}{c}\text { Highly } \\
\text { Acceptable }\end{array}$ \\
\hline Stage 1.3 & 3.57 & 3.57 & 3.42 & 3.96 & 3.87 & 0.87 & $\begin{array}{c}\text { Highly } \\
\text { Acceptable }\end{array}$ \\
\hline Stage 1.4 & 4.42 & 4.24 & 3.89 & 4.16 & 4.16 & 0.82 & $\begin{array}{c}\text { Highly } \\
\text { Acceptable }\end{array}$ \\
\hline Average & 3.89 & 3.53 & 3.44 & 3.95 & 3.86 & 0.93 & $\begin{array}{c}\text { Highly } \\
\text { Acceptable }\end{array}$ \\
\hline
\end{tabular}

\begin{tabular}{|c|c|c|c|c|c|c|c|}
\hline Stage 2 : Researcher \\
\hline Stage 2.1 & 4.29 & 3.77 & 3.65 & 4.06 & 4.00 & 0.82 & $\begin{array}{c}\text { Highly } \\
\text { Acceptable }\end{array}$ \\
\hline Stage 2.2 & 4.00 & 4.10 & 4.08 & 4.17 & 4.15 & 0.78 & $\begin{array}{c}\text { Highly } \\
\text { Acceptable }\end{array}$ \\
\hline Stage 2.3 & 4.27 & 4.04 & 4.12 & 4.17 & 4.15 & 0.85 & $\begin{array}{c}\text { Highly } \\
\text { Acceptable }\end{array}$ \\
\hline Average & 4.19 & 3.97 & 3.95 & 4.13 & 4.10 & 0.82 & $\begin{array}{c}\text { Highly } \\
\text { Acceptable }\end{array}$ \\
\hline
\end{tabular}

\begin{tabular}{|c|c|c|c|c|c|c|c|}
\multicolumn{6}{|c|}{ Stage 3 : Students } \\
\hline Stage 3.1 & 3.86 & 3.88 & 3.58 & 4.03 & 3.98 & 0.93 & $\begin{array}{c}\text { Highly } \\
\text { Acceptable }\end{array}$ \\
\hline Stage 3.2 & 3.71 & 3.50 & 3.39 & 3.91 & 3.82 & 0.89 & $\begin{array}{c}\text { Highly } \\
\text { Acceptable }\end{array}$ \\
\hline Stage 3.3 & 3.71 & 3.37 & 3.35 & 3.96 & 3.84 & 0.89 & $\begin{array}{c}\text { Highly } \\
\text { Acceptable }\end{array}$ \\
\hline Average & 3.76 & 3.58 & 3.44 & 3.97 & 3.88 & 0.90 & $\begin{array}{c}\text { Highly } \\
\text { Acceptable }\end{array}$ \\
\hline
\end{tabular}

Stage 4 : Project Support

\begin{tabular}{|r|c|c|c|c|c|c|c|}
\hline Stage 4.1 & 4.86 & 4.75 & 4.58 & 4.27 & 4.37 & 0.93 & $\begin{array}{c}\text { Highly } \\
\text { Acceptable }\end{array}$ \\
\hline Stage 4.2 & 4.71 & 4.71 & 4.65 & 4.30 & 4.38 & 0.85 & $\begin{array}{c}\text { Highly } \\
\text { Acceptable }\end{array}$ \\
\hline Stage 4.3 & 4.43 & 4.71 & 4.54 & 4.36 & 4.42 & 0.83 & $\begin{array}{c}\text { Highly } \\
\text { Acceptable }\end{array}$ \\
\hline Average & 4.67 & 4.72 & 4.59 & 4.31 & 4.39 & 0.87 & $\begin{array}{c}\text { Highly } \\
\text { Acceptable }\end{array}$ \\
\hline $\begin{array}{r}\text { Total } \\
\text { Average }\end{array}$ & 4.11 & 3.92 & 3.82 & 4.08 & 4.04 & 0.88 & $\begin{array}{c}\text { Highly } \\
\text { Acceptable }\end{array}$ \\
\hline
\end{tabular}

From the analysis of the overall level of satisfaction and acceptance of factors, it was found at a high level of agreement $(\mathrm{mean}=4.04$, S.D. $=0.88)$. Moreover, the level of satisfaction with the project is the highest $($ mean $=4.39$, S.D. $=0.87)$. Therefore, it can be concluded that the respondents agreed and accepted the teaching and learning as a senior project. From the data obtained from the respondents, the researchers grouped the data by clustering through the use of machine learning tools and data mining techniques, which consisted of three parts:

\section{a) K-Means}

The k-means is the most common algorithm used as an iterative refinement technique. It is also called Lloyd's algorithm [14], especially in the computer science community. The k-mean algorithm is performed by switching between two steps: (1) the www.astesj.com assignment step, which assigns each observation to the cluster with the closest mean. (2) updates the procedure which calculated the new means to be a centroid of observations in a cluster.

\section{b) Decision Tree}

The decision tree is one of the learning methods used in statistics, machine learning, and data mining. It works by determining the data from observations and separating data for use in data consideration and finding predictive results. The benefit is on getting important factors, which are caused by the nodes or the decision-making part of the model [15-16].

\section{c) Model Performance}

The goal of the model performance is to assess the results and review the process [15-16]. The tools are used in the research, including cross-validation methods as shown in Figure 4, and confusion matrix as mentioned in Figure 5.

Figure 4 displays the separation of data for evaluating the model. The cross-validation method divides the data into two parts. The first part is used for modeling and the remainder is applied to test the model. In addition, model evaluation requires a tool called a confusion matrix [16] to test the model's performance, with the principles shown in Figure 6.

Figure 5 presents the composition of the confusion matrix performance, which is composed of the actual class and the predicted class. An important benefit of the performance of the confusion matrix is the ability to determine the model's ability to predict results, such as the predictive ability or accuracy, model precision, model sensitivity, and model specificity (recall measurement). These values are used to determine the actual performance model. Moreover, Figure 5 also demonstrates the formulas and methods for calculating the various performance parameters in detail.

\section{3) Reporting Results}

From Table 6, the most attention toward the factors is the stage 4.3 budget support, which is the highest level of satisfaction (mean $=4.42$, S.D. $=0.83$ ). The second is the stage 4.2 staff support, which has a high level of satisfaction $($ mean $=4.38$, S.D. $=0.85)$. The lowest is the stage 1.1 organization policies, whereas the level of satisfaction is at the middle level (mean = 3.53, S.D. $=1.12$ ).

Interesting suggestions include that the budget is delayed and insufficient. Researchers are not very interested because they think it is difficult and not worth the money. Researchers who are truly interested in joining are few, most of whom participate because of their duties. There should be incentives to motivate participants and to develop research in the organization.

\section{Research Results and Discussion}

The research results classified the research report into four topics which are modelling results, model testing results, model applying results, and summarizing the significant factors.

\subsection{Modelling Results}

Modelling results are the reports of the various models on different criteria, including the depth of the decision tree, and types of cross-validation method tests, where the different results are shown in Table 7. 


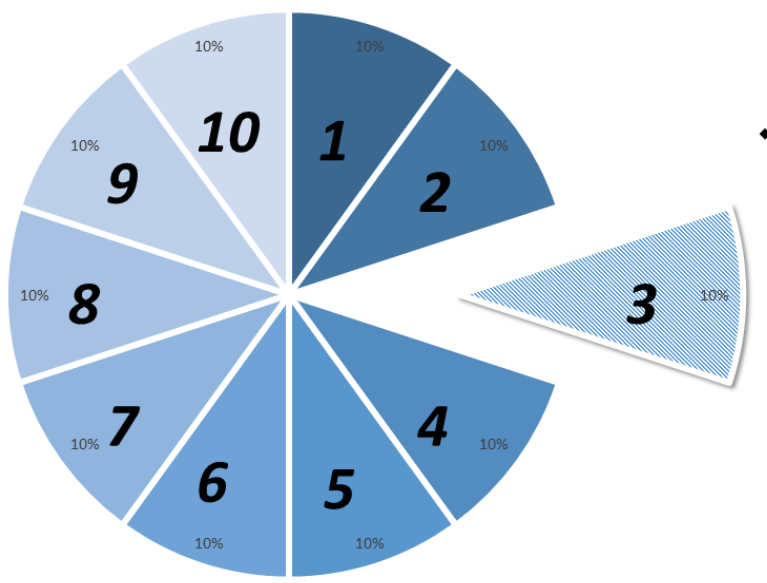

* Parts used for modeling

There are Part 1, Part 2, part 4, part 5, part 6, part 7, part 8, part 9, and part 10.

1 Part used for testing It is Part 3.

Figure 4: Cross-Validation Methods

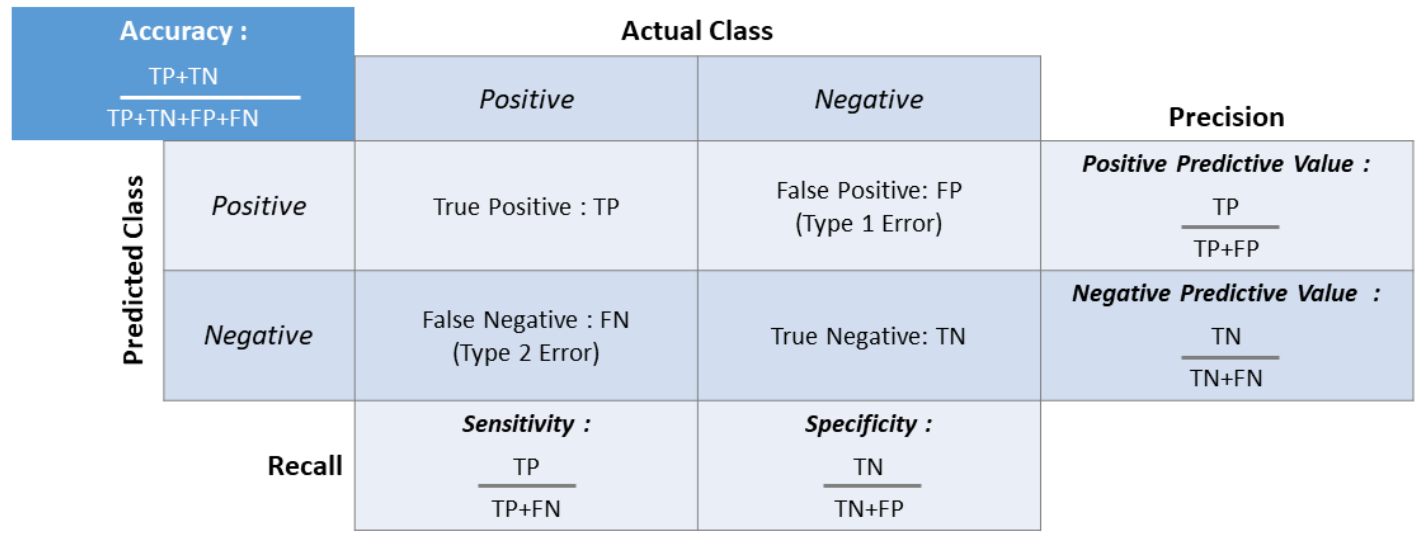

Figure 5: Confusion Matrix Performance

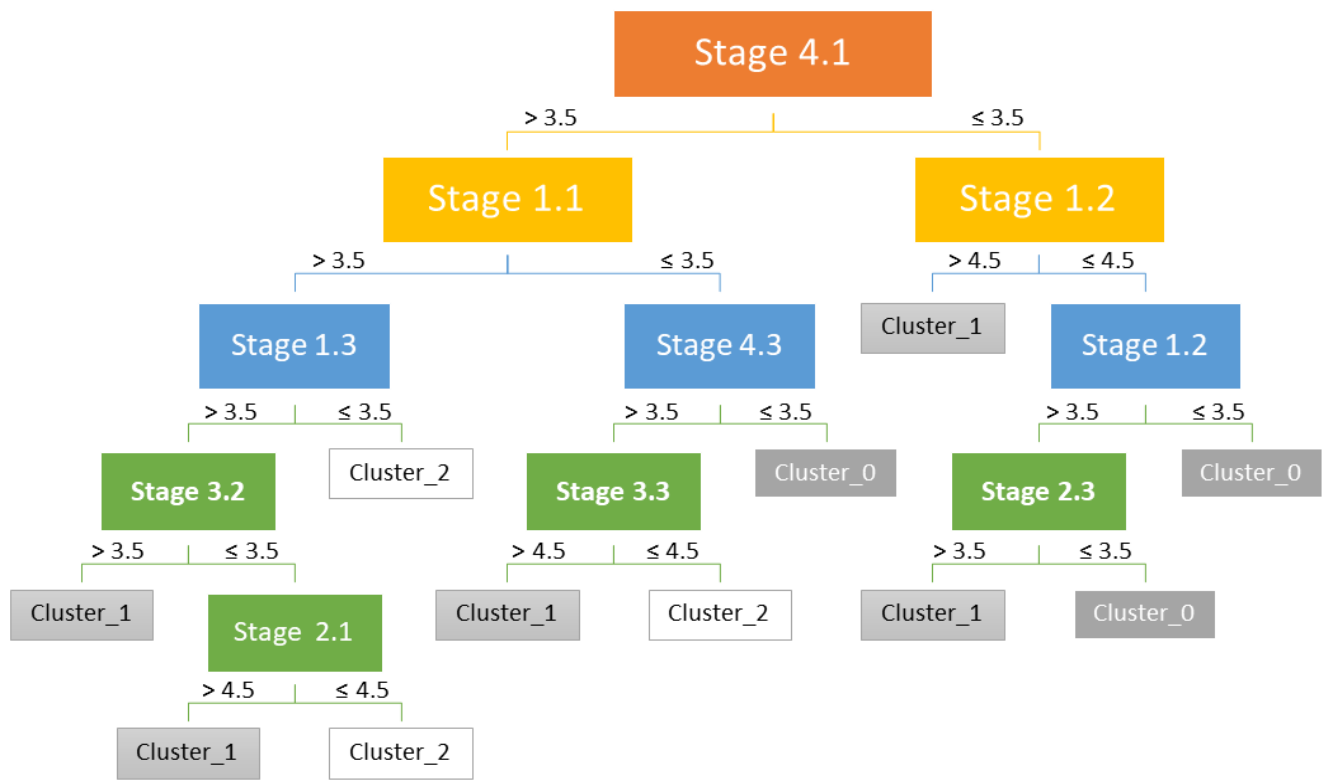

Figure 6: The decision tree model 
W. Nuankaew et al. / Advances in Science, Technology and Engineering Systems Journal Vol. 5, No. 4, $805-815$ (2020)

Table 7: Model results from k-means clustering

\begin{tabular}{|c|c|c|c|c|}
\hline \multirow{2}{*}{$\begin{array}{l}\text { Cluster } \\
\text { Number }\end{array}$} & \multirow{2}{*}{$\begin{array}{c}\text { Depth of } \\
\text { Decision Tree }\end{array}$} & \multicolumn{3}{|c|}{ Type of Cross-Validation Methods } \\
\hline & & 5-Fold & 10-Fold & Leave-one-out \\
\hline \multirow{7}{*}{ 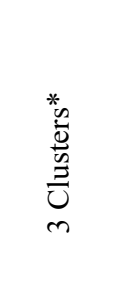 } & Level 3 & $90.51 \%$ & $92.21 \%$ & $92.66 \%$ \\
\hline & Level 4 & $95.91 \%$ & $95.88 \%$ & $96.33 \%$ \\
\hline & Level 5 & $95.90 \%$ & $96.53 \%$ & $96.98 \%$ \\
\hline & Level 6* & $96.12 \%$ & $96.75 \%$ & $98.06 \% *$ \\
\hline & Level 7 & $95.90 \%$ & $96.75 \%$ & $97.62 \%$ \\
\hline & Level 8 & $95.68 \%$ & $96.32 \%$ & $96.76 \%$ \\
\hline & Level 9 & $95.25 \%$ & $96.32 \%$ & $96.76 \%$ \\
\hline \multirow{7}{*}{ 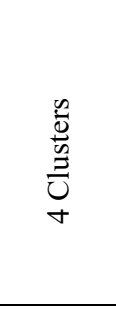 } & Level 3 & $71.30 \%$ & $76.01 \%$ & $81.21 \%$ \\
\hline & Level 4 & $87.25 \%$ & $86.63 \%$ & $82.51 \%$ \\
\hline & Level 5 & $88.33 \%$ & $89.00 \%$ & $84.88 \%$ \\
\hline & Level 6 & $89.62 \%$ & $89.65 \%$ & $86.83 \%$ \\
\hline & Level 7 & $89.41 \%$ & $90.09 \%$ & $88.12 \%$ \\
\hline & Level 8* & $89.85 \%$ & $90.52 \% *$ & $88.12 \%$ \\
\hline & Level 9 & $90.28 \%$ & $90.51 \%$ & $89.20 \%$ \\
\hline \multirow{7}{*}{$\underset{n}{\stackrel{\mathscr{J}}{\Xi}}$} & Level 3 & $61.99 \%$ & $61.97 \%$ & $61.12 \%$ \\
\hline & Level 4 & $77.73 \%$ & $78.83 \%$ & $81.64 \%$ \\
\hline & Level 5 & $87.69 \%$ & $87.25 \%$ & $85.96 \%$ \\
\hline & Level 6 & $87.04 \%$ & $87.90 \%$ & $85.53 \%$ \\
\hline & Level 7 & $87.70 \%$ & $88.33 \%$ & $87.26 \%$ \\
\hline & Level 8 & $88.78 \%$ & $86.83 \%$ & $87.26 \%$ \\
\hline & Level 9* & $89.21 \% *$ & $89.21 \%$ * & $87.69 \%$ \\
\hline
\end{tabular}

Table 7 shows that the k-means model with the highest accuracy is the decision tree model that is classified into 3 clusters by dividing the model testing into the leave-one-out crossvalidation method with a depth of 6 levels of the decision tree model and has an accuracy of $98.06 \%$

However, the test results classified by other clusters yield a lower accuracy. For example, the 4 clusters with the highest results are $90.52 \%$ and the 5 clusters have the highest results of $89.21 \%$.

\subsection{Model Testing Results}

From the results of the prototype model development, it can be concluded that the model with the highest accuracy is the development of the model from k-means clustering, with the appropriate number of 3 clusters and there is a leave-one-out crossvalidation result with an accuracy of $98.06 \%$. Details of the developed model are shown in Table 8.

Table 8: The model testing results

\begin{tabular}{|c|c|c|c|c|c|}
\hline \multirow{2}{*}{\multicolumn{2}{|c|}{$\begin{array}{c}\text { Accuracy: } \\
98.06 \% \\
(+/-13.82 \%)\end{array}$}} & \multicolumn{3}{|c|}{ Actual Class } & \multirow{3}{*}{$\begin{array}{c}\text { Precision } \\
\text { Class } \\
98.21 \%\end{array}$} \\
\hline & & \multirow{2}{*}{$\begin{array}{c}\begin{array}{c}\text { True } \\
\text { Cluster_l }\end{array} \\
220\end{array}$} & \multirow{2}{*}{$\begin{array}{c}\begin{array}{c}\text { True } \\
\text { Cluster_2 }\end{array} \\
3\end{array}$} & \multirow{2}{*}{$\begin{array}{c}\begin{array}{c}\text { True } \\
\text { Cluster_3 }\end{array} \\
1\end{array}$} & \\
\hline \multirow{3}{*}{$\begin{array}{l}n \\
0 \\
0 \\
0 \\
0 \\
0 \\
.00 \\
: 0 \\
0 \\
0\end{array}$} & $\begin{array}{c}\text { Pred. } \\
\text { Cluster_l }\end{array}$ & & & & \\
\hline & $\begin{array}{c}\text { Pred. } \\
\text { Cluster_2 }\end{array}$ & 4 & 179 & 1 & $97.28 \%$ \\
\hline & $\begin{array}{c}\text { Pred. } \\
\text { Cluster_3 }\end{array}$ & 0 & 0 & 55 & $100.00 \%$ \\
\hline \multicolumn{2}{|c|}{ Recall Class } & $98.21 \%$ & $98.35 \%$ & $96.49 \%$ & \\
\hline
\end{tabular}

\subsection{Model Applying Results}

From the model that has been selected and demonstrated the performance, this section shows the decision tree model in Figure 6 as displayed in the end of paper. The decision tree rules for selftesting are shown in the test results in Table 9, and the centroid of each cluster is shown in Table 10.

Table 9: The decision tree rules for self-testing

\begin{tabular}{|c|c|c|}
\hline Rule & Condition (If) & Prediction (Then) \\
\hline 1 & $\begin{array}{l}\text { If Stage } 4.1>3.500 \text { and Stage } \\
1.1>3.500 \text { and Stage } 1.3> \\
3.500 \text { and Stage } 3.2>3.500\end{array}$ & $\begin{array}{l}\text { Then, suitable for cluster_1 } 1= \\
99.52 \% \text {, and suitable for } \\
\text { cluster_2 }=0.48 \% .\end{array}$ \\
\hline 2 & $\begin{array}{l}\text { If Stage } 4.1>3.500 \text { and Stage } \\
1.1>3.500 \text { and Stage } 1.3> \\
3.500 \text { and Stage } 3.2 \leq 3.500 \text { and } \\
\text { Stage } 2.1>4.500\end{array}$ & $\begin{array}{l}\text { Then, suitable for cluster_1 }= \\
100 \% \text {. }\end{array}$ \\
\hline 3 & $\begin{array}{l}\text { If Stage } 4.1>3.500 \text { and Stage } \\
1.1>3.500 \text { and Stage } 1.3> \\
3.500 \text { and Stage } 3.2 \leq 3.500 \text { and } \\
\text { Stage } 2.1 \leq 4.500\end{array}$ & $\begin{array}{l}\text { Then, suitable for cluster_1 } 1= \\
12.50 \% \text {, and suitable for } \\
\text { cluster_2 }=87.50 \% \text {. }\end{array}$ \\
\hline 4 & $\begin{array}{l}\text { If Stage } 4.1>3.500 \text { and Stage } \\
1.1>3.500 \text { and Stage } 1.3 \leq \\
3.500\end{array}$ & $\begin{array}{l}\text { Then, suitable for cluster_ } 2= \\
100 \% \text {. }\end{array}$ \\
\hline 5 & $\begin{array}{l}\text { If Stage } 4.1>3.500 \text { and Stage } \\
1.1 \leq 3.500 \text { and Stage } 4.3> \\
3.500 \text { and Stage } 3.3>4.500\end{array}$ & $\begin{array}{l}\text { Then, suitable for cluster_ } 1= \\
60 \% \text {, and suitable for cluster_2 } \\
=40 \% \text {. }\end{array}$ \\
\hline 6 & $\begin{array}{l}\text { If Stage } 4.1>3.500 \text { and Stage } \\
1.1 \leq 3.500 \text { and Stage } 4.3> \\
3.500 \text { and Stage } 3.3 \leq 4.500\end{array}$ & $\begin{array}{l}\text { Then, suitable for cluster_1 = } \\
1.23 \% \text {, suitable for cluster_2 }= \\
98.15 \% \text {, and suitable for } \\
\text { cluster_3 } 3=0.62 \% .\end{array}$ \\
\hline 7 & $\begin{array}{l}\text { If Stage } 4.1>3.500 \text { and Stage } \\
1.1 \leq 3.500 \text { and Stage } 4.3 \leq \\
3.500\end{array}$ & $\begin{array}{l}\text { Then, suitable for cluster_3 } 3= \\
100 \% .\end{array}$ \\
\hline 8 & $\begin{array}{l}\text { If Stage } 4.1 \leq 3.500 \text { and Stage } \\
1.2>4.500\end{array}$ & $\begin{array}{l}\text { Then, suitable for cluster_1 }= \\
100 \% \text {. }\end{array}$ \\
\hline 9 & $\begin{array}{l}\text { If Stage } 4.1 \leq 3.500 \text { and Stage } \\
1.2 \leq 4.500 \text { and Stage } 1.2> \\
3.500 \text { and Stage } 2.3>3.500\end{array}$ & $\begin{array}{l}\text { Then, suitable for cluster_1 } 1= \\
100 \% .\end{array}$ \\
\hline 10 & $\begin{array}{l}\text { If Stage } 4.1 \leq 3.500 \text { and Stage } \\
1.2 \leq 4.500 \text { and Stage } 1.2> \\
3.500 \text { and Stage } 2.3 \leq 3.500\end{array}$ & $\begin{array}{l}\text { Then, suitable for cluster_3 } 3= \\
100 \% .\end{array}$ \\
\hline 11 & $\begin{array}{l}\text { If Stage } 4.1 \leq 3.500 \text { and Stage } \\
1.2 \leq 4.500 \text { and Stage } 1.2 \leq \\
3.500\end{array}$ & $\begin{array}{l}\text { Then, suitable for cluster_3 } 3= \\
100 \% .\end{array}$ \\
\hline \multicolumn{3}{|c|}{ Correct: 456 out of 463 training examples $(98.49 \%)$} \\
\hline
\end{tabular}

Table 10: The average within centroid of each cluster

\begin{tabular}{|c|c|c|c|}
\hline \multicolumn{4}{|c|}{ Stage and Cluster } \\
\hline Stages & Cluster 1 & Cluster 2 & Cluster 3 \\
\hline Stage 1. Organization & 4.43 & 2.68 & 2.74 \\
\hline Stage 1.1 & 4.49 & 3.49 & 2.60 \\
\hline Stage 1.2 & 4.48 & 3.48 & 2.70 \\
\hline Stage 1.3 & 4.43 & 4.24 & 2.81 \\
\hline Stage 1.4 & 4.48 & 3.82 & 2.68 \\
\hline Stage 2. Researcher & 4.45 & 4.19 & 2.84 \\
\hline Stage 2.1 & 4.51 & 4.12 & 2.84 \\
\hline Stage 2.2 & 4.50 & 3.70 & 2.86 \\
\hline Stage 2.3 & 4.44 & 3.34 & 2.93 \\
\hline Stage 3. Students 3.1 & 4.49 & 3.34 & 2.88 \\
\hline Stage 3.2
\end{tabular}


W. Nuankaew et al. / Advances in Science, Technology and Engineering Systems Journal Vol. 5, No. 4, 805-815 (2020)

\begin{tabular}{|c|c|c|c|}
\hline \multicolumn{5}{|l|}{ Stage 4. Project Support } \\
\hline Stage 4.1 & 4.44 & 4.91 & 2.37 \\
\hline Stage 4.2 & 4.41 & 4.87 & 2.74 \\
\hline Stage 4.3 & 4.45 & 4.87 & 2.88 \\
\hline Stage 4.4 & 4.44 & 4.91 & 2.37 \\
\hline Total Number of Items: 463 & 224 items & 182 items & 57 items \\
\hline
\end{tabular}

\subsection{Summarize the Significant Factors}

From the data collection, there were 463 people who provided attitudes and satisfaction to the research. It can be concluded that the overall level of satisfaction is accepted (mean $=4.04$, S.D. $=$ 0.88 ), as shown in Table V. Therefore, it can be concluded that the respondents agreed and accepted the teaching and learning as a senior project. In addition, the prototype model has been developed for predicting the highest accuracy levels $(98.06 \%)$ : shown in Table VI and Table VII. Moreover, the results of the self-test data model are very accurate at the highest level, which is equal to 98.49\% (Correct: 456 out of 463 training examples) as shown in Table VIII. Therefore, it can be concluded that this study was successful. It can develop highly accurate models and also have high performance model testers.

Finally, the significant factors from this research are composed of nine factors as follows: Stage 1.1 The policies of the organization, Stage 1.2 The vision of the organization, Stage 1.3 The mission of the organization, Stage 2.1 Experience and achievements of researchers, Stage 2.3 Qualifications of Research Team, Stage 3.2 Interest in the research topics, Stage 3.3 Impressions and examples in the past, Stage 4.1 Technology and laboratory support, and Stage 4.3 Budget support.

From clustering and discovering these significant factors, the researcher can use the research results to develop a program for advising advisors in a serious project course in order to effectively pair with students having a common attitude.

\subsection{Research Discussions}

The research discussions are divided into three points: (1) A proactive learning culture and learning style model development, (2) Scientific aspects of educational data mining, and (3) Utilization of research activities and research results.

1) A proactive learning culture and learning style model development

The reason for the researchers emphasizing on the model development and data analysis was because the research team was assembled from many institutions but encountered the same problem. Our common problem is to recommend suitable teachers to students in senior projects. Therefore, this research focused on solving problems proactively using proactive learning strategies to create opportunities for corrective action and reducing impropriety. In addition, the professional group of the researchers is in the information technology field where the effort is on using technology to help solve problems.

\section{2) Scientific aspects of educational data mining}

In the process of developing research instruments tool, researchers examined questionnaires through the researchers' organization according to procedures and standards of the research process. Questionnaires are routinely used to assess teaching and

learning. It is conducted on an annual basis. The past assessments are only through statistical analysis, not analyzed for improvement and problem solving. In this research, the researchers analyzed the results of stakeholder assessments in order to form a correlation group and present the stakeholders on further improving the curriculum, and teaching and learning management.

In the conclusion of scientific aspects of educational data mining, the use of available information is important and necessary.

\section{3) Utilization of research activities and research results}

From the research process and routine operations of the organization, the researcher found that the organizational management and its members realized the importance of conducting this research. In addition, the models in Figure 6, the decision tree model, and Table 9 decision tree rules for self-testing can be further developed into computer programs, applications, and technological applications.

One of the obvious benefits of research is engagement within the organization. It makes the people in the organization aware of the importance of applying technology. In addition, students who participate in the project can also apply the knowledge gained in future students' lives and work.

\section{Conclusion}

From this research, the researcher can summarize according to the research objectives as follows: (1) to survey attitude and perception, which is a collaboration between researchers and students, (2) to develop a model for clustering of advisors and students, and (3) to develop factors that are significant to predict the right match in senior projects course. The results of the survey attitude and perception, which is a collaboration between researchers and students is shown in Table V. The result is that respondents have a high level of overall satisfaction (mean $=4.04$, S.D. $=0.88)$. Thus, it can be concluded that the respondents agreed and accepted the teaching and learning as a senior project.

The result of model development of the clustering model is for matching advisors and students. The result is that the model has the highest level of accuracy (98.06\%) as shown in Table VI and Table VII. Moreover, the results of the self-test data model are very accurate at the highest level, which is equal to $98.49 \%$ (Correct: 456 out of 463 training examples) as shown in Table VIII.

The result with the development of the factors are significant to predict the right match in senior projects course. The result is an important factor consisting of nine factors, which are stage 1.1 the policies of the organization, stage 1.2 the vision of the organization, stage 1.3 the mission of the organization, stage 2.1 experience and achievements of researchers, stage 2.3 qualifications of research team, stage 3.2 interest in the research topics, stage 3.3 Impressions and examples in the past, stage 4.1 technology and laboratory support, and stage 4.3 budget support.

Therefore, from the research study on collecting data Rajabhat Mahasarakham University, the Maha Sarakham University, and the University of Phayao with a total of 463 samples, this work concludes that the objectives have been achieved with the four machine learning tools and data mining techniques: k-means, decision tree, cross-validation methods, and confusion matrix. For 
future research projects, the researchers are committed to further studying on the development of learners' achievement and aims to promote a learning culture based on the results of this research and active learning of educational institutions.

\section{Author Contributions}

Wongpanya Nuankaew, Kanakarn Phanniphong and Sittichai Bussaman designed the research problems and research framework; Wongpanya Nuankaew and Pratya Nuankaew collected the data; Pratya Nuankaew and Direk Teeraputon analyzed the data and constructed the clustering models; Pratya Nuankaew wrote the paper and all authors had approved the final version; Pratya Nuankaew is responsible for communicating and delivering the research to the journals.

\section{Conflict of Interest}

The authors declare no conflict of interest.

\section{Acknowledgment}

This research is supported by the five organizations: (1) Faculty of Information Technology, Rajabhat Mahasarakham University, Maha Sarakham, 44000, Thailand. (2) Faculty of Business Administration and Information Technology, Rajamangala University of Technology Tawan-Ok, Chonburi, 20110, Thailand. (3) Faculty of Science and Technology, Rajabhat Mahasarakham University, Maha Sarakham, 44000, Thailand. (4) School of Education, University of Phayao, Phayao, 56000, Thailand. (5) School of Information and Communication Technology, University of Phayao, Phayao, 56000, Thailand. The researchers would like to thank the advisor, lecturers, students, technicians, and all respondents for their entire support.

\section{References}

[1] P. Nuankaew, P. Temdee, "Matching of compatible different attributes for compatibility of members and groups" Int. J. Mob. Learn. Organ., 13(1), 429, 2019. https://doi.org/10.1504/IJMLO.2019.096469.

[2] P. Nuankaew, W. Nuankaew, K. Phanniphong, S. Imwut, S. Bussaman, "Students Model in Different Learning Styles of Academic Achievement at the University of Phayao, Thailand" Int. J. Emerg. Technol. Learn. IJET, 14(12), 133-157, 2019. https://doi.org/10.3991/ijet.v14i12.10352.

[3] F. M. van der Kleij, "Comparison of teacher and student perceptions of formative assessment feedback practices and association with individual student characteristics" Teach. Teach. Educ., 85, 175-189, Oct. 2019. http://doi.org/10.1016/j.tate.2019.06.010.

[4] C. Brandmiller, H. Dumont, and M. Becker, "Teacher Perceptions of Learning Motivation and Classroom Behavior: The Role of Student Characteristics" Contemp. Educ. Psychol., 101893, 2020. http://doi.org/10.1016/j.cedpsych.2020.101893.

[5] C.-Y. Chen and P. P. Chong, "Software engineering education: A study on conducting collaborative senior project development" J. Syst. Softw., 84(3), 479-491, 2011. http://doi.org/10.1016/j.jss.2010.10.042.

[6] D. A. Morley, "Enhancing networking and proactive learning skills in the first year university experience through the use of wikis" Nurse Educ. Today, 32(3), 261-266, 2012. http://doi.org/10.1016/j.nedt.2011.03.007.

[7] I. Gnizy, E. Baker William, and Grinstein Amir, "Proactive learning culture: A dynamic capability and key success factor for SMEs entering foreign markets," International Marketing Review, 31(5), 477-505, 2014. https://doi.org/10.1108/IMR-10-2013-0246.

[8] B.-K. Joo and T. Lim, "The Effects of Organizational Learning Culture, Perceived Job Complexity, and Proactive Personality on Organizational Commitment and Intrinsic Motivation," Journal of Leadership \& Organizational Studies, 16(1), 48-60, Aug. 2009. https://doi.org/10.1177/1548051809334195.
[9] A. Ruiz-Iniesta, G. Jimenez-Diaz, M. Gomez-Albarran, "Recommendation in Repositories of Learning Objects: A Proactive Approach that Exploits Diversity and Navigation-by-Proposing" in 2009 Ninth IEEE International Conference on Advanced Learning Technologies, 543-545, 2009. http://doi.org/10.1109/ICALT.2009.23.

[10] D. Gallego, E. Barra, S. Aguirre, G. Huecas, "A model for generating proactive context-aware recommendations in e-Learning systems" in 2012 Frontiers in Education Conference Proceedings, 1-62012, 2012. http://doi.org/10.1109/FIE.2012.6462246.

[11] M. Reuter et al., "Learning Factories' Trainings as an Enabler of Proactive Workers' Participation Regarding Industrie 4.0" Procedia Manuf., 9, 354 360, 2017. http://doi.org/10.1016/j.promfg.2017.04.020.

[12] S. Moon, J. G. Carbonell, "Proactive learning with multiple class-sensitive labelers" in 2014 International Conference on Data Science and Advanced $\begin{array}{llll}\text { Analytics } & \text { (DSAA), } & \end{array}$ http://doi.org/10.1109/DSAA.2014.7058048.

[13] P. Chapman, J. Clinton, R. Kerber, T. Khabaza, T. Reinartz, C. Shearer, R. Wirth, "Promoting reading comprehension and critical-analytic thinking: A comparison of three approaches with fourth and fifth graders" Contemp. Educ. Psychol., 46, 101-115, 2016 . http://doi.org/10.1016/j.cedpsych.2016.05.002.

[14] P. Nuankaew, P. Temdee, "Of online community: Identifying mentor and mentee with compatible different attributes and decision tree" in 2015 12th International Conference on Electrical Engineering/Electronics, Computer, Telecommunications and Information Technology (ECTI-CON), 1-6, 2015. http://doi.org/10.1109/ECTICon.2015.7207130.

[15] P. Nuankaew, P. Temdee, "Determining of compatible different attributes for online mentoring model" in 2014 4th International Conference on Wireless Communications, Vehicular Technology, Information Theory and Aerospace Electronic Systems (VITAE), 1-5, 2014 http://doi.org/10.1109/VITAE.2014.6934434.

[16] P. Nuankaew, W. Nuankaew, T. Thamma, "The Recommended System for the Relationship between Educational Programs and Stu-dents' Interests" in International Conference on Digital Arts, Media and Technology, 2-3, 2016.

[17] W. Tan, A. Tang, T. Wang, W. Tan, L. Li, Z. Zhang, "An Overall Lifecycle Modeling Method for E-Learning Services and the Cooperative Mechanism Based on PCDA" in 2013 IEEE International Conference on Systems, Man, and Cybernetics, 669-674, 2013. http://doi.org/10.1109/SMC.2013.119.

[18] D. A. Vidhate, P. Kulkarni, "Performance enhancement of cooperative learning algorithms by improved decision making for context based application" in 2016 International Conference on Automatic Control and Dynamic Optimization Techniques (ICACDOT), 246-252, 2016. http://doi.org/10.1109/ICACDOT.2016.7877588.

[19] C.-T. Chang, C.-Y. Tsai, S.-E. Peng, H.-H. Tsai, P.-T. Yu, "On the Design of Multi-User Streaming Feedback System for Application of Cooperative Learning" in 2016 International Computer Symposium (ICS), 656-659, 2016. http://doi.org/10.1109/ICS.2016.0134.

[20] P. Maresca, E. Gómez, J. Caja, C. Barajas, R. Ledesma, "Academic Learning Platform for Practical Classes: A Learning Model in Manufacturing Engineering" Procedia Eng., 132, 205-212, 2015. http://doi.org/10.1016/j.proeng.2015.12.471.

[21] A. Bouabid, P. Vidal, J. Broisin, "Integrating Learning Management Systems and Practical Learning Activities: The Case of Computer and Network Experiments" in 2009 Ninth IEEE International Conference on Advanced Learning Technologies, 398-402, 2009. http://doi.org/10.1109/ICALT.2009.181.

[22] A. Mathew, V. Pangracious, A. Varghese, A. Thomas, D. Mathew, J. George, "PROJECT HAWK: An innovative introduction of practical learning and entrepreneurship in engineering education" in 2012 2nd Interdisciplinary Engineering Design Education Conference (IEDEC), 34-40, 2012. http://doi.org/10.1109/IEDEC.2012.6186919.

[23] A. Smith, C. Bluck, "Multiuser Collaborative Practical Learning Using Packet Tracer" in 2010 Sixth International Conference on Networking and Services, 356-362, 2010. http://doi.org/10.1109/ICNS.2010.56.

[24] G. Hamerly J. Drake, "Accelerating Lloyd's algorithm for k-means clustering" in Partitional clustering algorithms, Springer, 41-78, 2015. https://doi.org/10.1007/978-3-319-09259-1_2.

[25] P. Nuankaew, W. Nuankaew, P. Temdee, "Institution recommendation using relationship optimisation between program and student context" Int. J. $\begin{array}{llll}\text { High. } & \text { Educ. } & \text { Sustain., 2(4), 279-302, } & \end{array}$ https://doi.org/10.1504/IJHES.2019.103365.

[26] P. Nuankaew, W. Nuankaew, K. Phanniphong, R. Fooprateepsiri, S. Bussaman, "Analysis Dropout Situation of Business Computer Students at University of Phayao" in The Impact of the 4th Industrial Revolution on 
W. Nuankaew et al. / Advances in Science, Technology and Engineering Systems Journal Vol. 5, No. 4, 805-815 (2020)

Engineering Education, Cham, 419-432, 2020. http://doi.org/10.1007/9783-030-40274-7 42.

[27] P. Nuankaew, "Dropout Situation of Business Computer Students, University of Phayao" Int. J. Emerg. Technol. Learn. IJET, 14(19), 2019. https://doi.org/10.3991/ijet.v14i19.11177. 